12 Hillbom $M$, Kaste $M$. Does ethanol intoxication promote brain infarction in young adults? Lancet 1978;ii:1181-3.

13 Jick $\mathrm{H}$, Porter J, Rothman KJ. Oral contraceptives and nonfatal stroke in healthy young women. Ann Intern Med 1978;89:58-60.

14 Lidegaard $\emptyset$. Thromboembolic insults in the central nervous system and ora contraceptives. Ugeskr Laeger 1982;144:2769-71.

15 Hart RG, Miller VT. Cerebral infarction in young adults: a practical approach. Stroke 1983;14:110-4.

16 Mettinger $\mathrm{KJ}$, Söderström CE, Neiman J. Stroke before 55 years of age a Karolinska Hospital 1973-77. A study of 388 well-defined cases. Acta Neurol Scand 1984;70:415-22

17 Oleckno WA. The risk of stroke in young aduits: an analysis of the contribution of cigarette smoking and alcohol consumption. Public Health 1988;102:45-55

18 Thorogood M, Mann J, Murphy M, Vessey M. Fatal stroke and use of oral contraceptives: findings from a case-control study. $\mathrm{Am}$ f Epidemiol 1992; 136:35-45.

19 Layde PM, Ory HW, Beral V, Kay CR. Incidence of arterial disease among oral contraceptive users. $\mathcal{F} R$ Coll Gen Pract 1983;33:75-82.

20 Vessey MP, Lawless M, Yeates D. Oral contraceptives and stroke: findings in a large prospective study. $B M \mathcal{F} 1984 ; 289: 530-1$.

21 Kay CR. Royal College of General Practitioners' oral contraception study: some recent observations. Clin Obstet Gynecol 1984;11:759-86.

22 Wermuth N, Lauritzen SL. Graphical and recursive models for contingency tables. Biometrika 1983;70:537-52.

23 Kreiner S. Analysis of multidimensional contingency tables by exact conditional tests. Techniques and strategy. Scandinavian fournal of Statistics 1987;14:97-112.

24 Whittabev J. Graphical models in applied multivariate statistics. New York: John Wiley, 1990

25 Glass R, Johnson B, Vessey M. Accuracy of recall of histories of oral contraceptive use. Br F Prev Soc Med 1974;28:273-5.

26 Stolley PD, Tonascia JA, Sartwell PE, Tockman MS, Tonascia S, Rutledge A, et al. Agreement rates between oral contraceptive users and prescribers in relation to drug use histories. Am I Epidemiol 1978;107:226-35.

27 Rosenberg MJ, Layde PM, Ory HW, Strauss LT, Rooks JB, Rubin GL Agreement between women's histories of oral contraceptive use and Agreement between women's histories of

28 Coulter A, Vessey M, McPherson K. The ability of women to recall their oral contraceptive histories. Contraception 1986;33:127-37.

29 Realini JP, Goldzieher JW. Oral contraceptives and cardiovascular disease: a critique of the epidemiological studies. Am F Obstet Gynecol 1985;152: 729-98.

30 Mishell DR. Correcting misconceptions about oral contraceptives. Am $\mathcal{J}$ Obstet Gynecol 1989;161:1385-9.

31 Stolley PD, Strom BL, Sartwell PE. Oral contraceptives and vascular disease. Epidemiol Rev 1989;11:241-3.

32 Gerstman BB, Piper JM, Tomita DK, Ferguson WJ, Stadel BV, Lundin FE Oral contraceptive estrogen dose and the risk of deep venous thromboembolic disease. Am J Epidemiol 1991;133:32-6.

33 Abu-Zeid HAH, Choi NW, Maini KK, Nelson NA. Incidence and epidemiologic features of cerebrovascular disease (stroke) in Manitoba, Canada. Prev Med 1975;4:567-78.

34 Harmsen P, Berglund G, Larsson O, Tibblin G, Wilhelmsen L. Stroke registration in Göteborg, Sweden, 1970-75. Acta Med Scand 1979;206: 337-44.
35 Arbuckle DD, Harris RI, Goldacre MJ. Stroke in people under 55 years of age. Public Health 1982;96:96-100.

36 Lidegaard $\emptyset$, Søe M, Andersen MVN. Cerebral thromboembolism among young women and men in Denmark 1977-1982. Stroke 1986;17:670-5.

37 Anderson TW. Oral contraceptives and female mortality trends. Can Med Assoc f 1970;102:1156-60

38 Böttiger LE, Westerholm B. Oral contraceptives and thromboembolic disease. Acta Med Scand 1971;190:455-63.

39 Markush RE, Turner RN, Epidemiology of exogenous estrogens. HSMHA Health Reports 1971;86:74-86.

40 Gram LF, Kovács I, Pedersen A. Oral and intrauterine contraceptives. Use and adverse reactions. Ugeskr Laeger 1976;138:1133-9.

41 Wiseman RA. Absence of correlation between oral contraceptive usage and cardiovascular mortality. Int f Feril 1984;29:198-217.

42 Lidegaard $\emptyset$. Cerebrovascular deaths before and after the appearance of oral contraceptives. Acta Neurol Scand 1987;75:427-33.

43 Colditz GA, Bonita R, Stampfer MJ, Willet WC, Rosner B, Speizer FE, et al. Cigarette smoking and risk of stroke in middle-aged women. $N$ Engl $\mathcal{F}$ Med 1988;318:937-41.

44 Boysen G, Nyboe J, Appleyard M, Sorensen PS, Boas J, Somnier F, et al. Stroke incidence and risk factors for stroke in Copenhagen, Denmark. Stroke 1988;19:1345-53.

45 Bonita R, Scragg R, Stewart A, Jackson R, Beaglehole R. Cigarette smoking and risk of premature stroke in men and women. $B M 7$ 1986;293:6-8.

46 Abu-Zeid HAH, Choi NW, Maini KK, Hsu P-H, Nelson NA. Relative role of factors associated with cerebral infarction and cerebral hemorrhage. Strok 1977;8:106-12

47 Wolf PA, D'Agostino RB, Kannel WB, Bonita R, Belanger AJ. Cigarette smoking as a risk factor for stroke. $\mathcal{F} A M A 1988 ; 259: 1025-9$.

48 Nomura A, Constock GW, Kuller L, Tonascia JA. Cigarette smoking and strokes. Stroke 1974;5:483-6.

49 Kannel WB, Dawber TR, Cohen ME, McNamara PM. Vascular disease of the brain-epidemiologic aspects: the Framingham study. Am $\mathcal{f}$ Public Healt 1965;55:1355-66.

50 Salonen JT, Puska P, Tuomilehto J, Homan K. Relation of blood pressure, serum lipids, and smoking to the risk of cerebral stroke. Stroke 1982;13 $327-33$

51 Herman B, Schmitz PIM, Leyten ACM, Luijk JHV, Frenken CWGM, Op De Coul AAW, et al. Multivariate logistic analysis of risk factors for stroke in Tilburg, the Netherlands. Am I Epidemiol 1983;118:514-25.

52 Aho K, Reunanen A, Aromaa A, Knekt P, Maatela J. Prevalence of stroke in Finland. Stroke 1986;17:681-6.

53 Doll R, Gray R, Hafner B, Peto R. Mortality in relation to smoking: 22 years' observation on female British doctors. BMY 1980;280:967-71.

54 Darroch JN, Lauritzen SL, Speed TP. Markov fields and $\log$ linear interaction models for contingency tables. Anals of Statistics 1983;8:522-39.

55 Wermuth N, Lauritzen S. On substantive research hypotheses, conditional independence graphs and graphical chain models. Fournal of the Royal Statistical Society 1990;52:21-50.

56 Agresti A. Analysis of ordinal categorical data. New York: Wiley, 1984

57 Kreiner $S$. Analysis of multidimensional contingency tables by exact conditional tests. Techniques and strategies. Scandinavian foumal of Statistics 1987;14:97-112.

(Accepted 25 January 1993)
Department of Psychology, St George's Hospital

Medical School, London

SW17 ORE

Derek W Johnston, $M R C$

external scientific staff

Anne Gold, clinical

psychologist

John Kentish, clinical

psychologist

Deana Smith, research

assistant

Deepti Shah, research

assistant

\section{Department of}

Pharmacology and Clinical

Pharmacology

Patrick Vallance, senior

lecturer in clinical

pharmacology

Brian Robinson, emeritus

professor of cardiovascular

medicine

Department of Cardiology

Graham Leach, senior lecturer in bioengineering

Correspondence to:

Professor D W Johnston,

Department of Psychology,

University of St Andrews,

St Andrews, Fife KY16 9JU.

$B M \mathcal{F}$ 1993;306:963-66

\title{
Effect of stress management on blood pressure in mild primary hypertension
}

Derek W Johnston, Anne Gold, John Kentish, Deana Smith, Patrick Vallance, Deepti Shah, Graham Leach, Brian Robinson

\section{Abstract}

Objective-To establish whether stress management had a larger effect than a control treatment on resting blood pressure, ambulatory blood pressure, and left ventricular mass.

Design-A 12 week baseline period of habituation to measurement of blood pressure was followed by randomisation to either stress management or mild exercise for six months and follow up six months later.

Setting-General practice, district general hospital, and medical school.

Patients-Of the 184 patients aged under 60 with mild primary hypertension who entered the baseline habituation period, 88 were excluded because they failed to meet the entry criteria or they withdrew from the study. The remaining 46 men and 50 women underwent treatment.

Interventions -10 clinical sessions and daily practice at home of either stress management based on relaxation or non-aerobic stretching exercises. Mildly stressful 15 minute interviews before and after treatment.

Main outcome measures-Diastolic and systolic blood pressure in the clinic and during 12 hours of ambulatory recording, and left ventricular mass measured by echocardiography.

Results-The patients' blood pressure fell during habituation (systolic pressure from $152 \mathrm{~mm} \mathrm{Hg}$ to $140 \mathrm{~mm} \mathrm{Hg}$, diastolic pressure from 98 to $93 \mathrm{~mm} \mathrm{Hg}$ ), but neither resting nor ambulatory blood pressure was changed by the treatments. Left ventricular mass was also unchanged. Blood pressure rose during the stressful interview, but this rise was reduced by stress management (systolic pressure rose by $7.4 \mathrm{~mm} \mathrm{Hg}$ before treatment and by 3.7 mm Hg after treatment).

Conclusion-Stress management of a type advocated for treating mild primary hypertension is ineffective in lowering blood pressure in patients who are well habituated to measuring blood pressure.

\section{Introduction}

Raised blood pressure is associated with increased risk of cardiovascular disease. Even the mild increases in blood pressure found in up to a fifth of adults are associated with a higher incidence of myocardial 
infarction and stroke. ${ }^{1}$ Pharmacological treatments that lower blood pressure, however, do not have a substantial effect on the risk of coronary heart disease or overall mortality in patients with borderline or mild hypertension. ${ }^{23}$ The drugs may be associated with pronounced side effects that may offset the beneficial effects on blood pressure. ${ }^{4}$ Consequently various behavioural methods of reducing blood pressure have been advocated, many entailing some form of stress management based on relaxation..$^{5-12}$ In many of these studies blood pressure was apparently reduced by stress management, ${ }^{13}$ and one study showed that stress management might reduce cardiovascular morbidity. ${ }^{14}$ These studies, however, variously suffer from small sample sizes, inadequate control groups, short baseline periods with infrequent measurements of blood pressure (so that blood pressure may not have stabilised before treatment), and reliance on casual measurement of blood pressure at clinics (which might have been more readily influenced by relaxation techniques).

We carried out a randomised controlled trial of a standardised form of stress management in patients with untreated primary hypertension recruited in general practice. Stress management was compared with a programme of mild stretching exercises, which shared many non-specific elements with stress management and therefore served as a useful control.

\section{Subjects and methods}

Seven general practices referred patients for inclusion in the study if their diastolic blood pressure on at least two out of three occasions in one month was $90-104 \mathrm{~mm} \mathrm{Hg}$ if they were aged $35-59$ or $85-$ $104 \mathrm{~mm} \mathrm{Hg}$ if they were aged 18-34. If patients were referred with slightly higher blood pressures than those specified they were included in the baseline phase of the study but were excluded if their blood pressures were still too high at the end of this phase. We also excluded patients who had received antihypertensive drugs in the previous six months; had a history of coronary heart disease; were more than $70 \%$ over the desirable weight for their height, sex, and frame $e^{15}$; or consumed more than 60 units of alcohol a week if a man or 40 a week if a woman. A member of the research team interviewed the patients to explain the purpose of the study, to obtain their informed consent, and to train them to take their own blood pressure while seated. The patients then measured their blood pressure twice daily for three months with an aneroid sphygmomanometer with built in stethoscope so that they were habituated to the procedure. They returned their records monthly to us by post, and they also attended the hospital for a medical examination to be screened for secondary hypertension or concurrent illness requiring treatment. At this examination we drew blood samples for measurement of random cholesterol and creatinine concentrations, liver function tests, and a full blood count. We also measured blood pressure, recorded an electrocardiogram, and estimated left ventricular mass by $M$ mode echocardiography.

At the end of the three month baseline phase the patients were seen for a formal assessment and allocation to treatment by one of two assessors, who were trained in measuring blood pressure. After the patients had rested for five minutes their blood pressure was measured three times while they were seated with a Hawksley random zero sphygmomanometer and an appropriately sized cuff. The patients' blood pressure was also determined every 30 minutes from $10 \mathrm{am}$ to $10 \mathrm{pm}$ on a normal working day with an A and D 2240 ambulatory blood pressure sphygmomanometer. Patients were admitted to the study if the mean diastolic pressure (phase $\mathrm{V}$ ) of the second and third readings obtained with the patients resting was within the pressures specified for entry into the study or if the median ambulatory diastolic pressure was 85$104 \mathrm{~mm} \mathrm{Hg}$ for patients aged 35-59 and $80-104 \mathrm{~mm} \mathrm{Hg}$ for patients aged 18-34. Patients with a mean resting systolic pressure over $170 \mathrm{~mm} \mathrm{Hg}$ were excluded.

The patients' blood pressure was also measured with a Takeda UA751 automatic sphygmomanometer before and after a mildly stressful interview of 15 minutes' duration designed to elicit type A behaviour. ${ }^{16}$ Measurements with the Hawksley and Takeda sphygmomanometers were repeated at the end of treatment by the same assessors, who were blind to the treatments the patients had received, and ambulatory blood pressure was also recorded. Six months later follow up assessment was carried out, in which resting blood pressure was measured with Hawksley and Takeda sphygmomanometers.

The patients were allocated to a treatment and a therapist with a minimisation algorithm to balance the groups. ${ }^{17}$ The binary balancing criteria used were sex, resting diastolic pressure of $95 \mathrm{~mm} \mathrm{Hg}$ (Hawksley sphygmomanometer), ambulatory diastolic pressure of $90 \mathrm{~mm} \mathrm{Hg}$, age 35 , body weight $120 \%$ of the ideal weight, and alcohol consumption of 14 units a week for women and 21 for men.

The patients were treated individually and usually in a general practice unless they preferred to be seen at the hospital. They attended 10 sessions, each lasting about 30 minutes, over six months with eight of the sessions in the first three months. Stress management was based primarily on passive relaxation, meditation, and the use of relaxation in daily life. It followed the protocol developed by Patel and colleagues, ${ }^{56}$ and we had used it before. ${ }^{18}$ The patients received a booklet describing the stages of the treatment and were encouraged to practise daily and to keep records of the time spent and their success. The control programme of mild exercises was designed to match the stress management as closely as possible. These patients also received a booklet and were encouraged to keep a record of the exercises practised at home. The simple stretching exercises were designed to increase mobility and were not aerobic exercises that might be expected to have a direct effect on blood pressure. They were designed to use most of the main muscle groups and comprised simple procedures such as rotation of the head, shoulder, arm, and trunk; ankle rotation and toe pointing; and leg raising and swinging while resting against a chair or table. The patients gradually increased the range of exercises they carried out and the number of repetitions. The therapists (DWJ, AG, and JK), who carried out both treatments, were clinical psychologists experienced in using methods based on relaxation.

The differences between the groups before treatment were tested by uncorrelated $t$ test. Changes in each group during treatment were tested by correlated $t$ test. The differences between the groups after treatment were tested by analysis of covariance with the pretreatment value of the variable being analysed as the covariate. The effect of the stressful interview on the two groups was analysed by repeated measure analysis of variance with the two repeated measures being before and after the interview and before and after treatment. The type of treatment was the between subject factor. Weight was controlled for in all comparisons of left ventricular mass.

\section{Results}

Of the 184 patients who were referred to the study and who entered the baseline phase, 88 were excluded from treatment: 32 whose blood pressure was too low; 13 whose blood pressure was too high; six who 
exceeded the criteria for weight or alcohol consumption; seven with suspected secondary hypertension or coexistent disease requiring treatment; and 30 who withdrew from the study. Of the 96 patients remaining, 48 were allocated to stress management and 48 to mild exercise.

The two groups were well matched for weight, age, blood pressure, left ventricular mass, serum cholesterol concentration, and $\gamma$-glutamyltransferase activity (table I). We mistakenly treated one patient whose systolic blood pressure was above the limit specified, and we withdrew her from the study after the posttreatment assessment. Five patients practising stress management dropped out of the study, as did seven

TABLE I-Characteristics of mildly hypertensive patients randomised to either stress management or mild exercise

\begin{tabular}{|c|c|c|c|c|}
\hline & \multicolumn{2}{|c|}{ Stress management $(n=48)$} & \multicolumn{2}{|c|}{ Mild exercise $(n=48)$} \\
\hline & Mean (SD) & Range & Mean (SD) & Range \\
\hline No of men & 24 & & 22 & \\
\hline Age (years) & $45.8(7.9)$ & $31-59$ & $47.4(8.9)$ & $23-59$ \\
\hline \multicolumn{5}{|c|}{ Mean blood pressure at referral $(\mathrm{mm} \mathrm{Hg})$ : } \\
\hline Systolic & $151.9(19.9)^{\star}$ & $125-200$ & $151 \cdot 8(13 \cdot 7) \dagger$ & $130-180$ \\
\hline Diastolic & $97 \cdot 7(6 \cdot 5)^{\star}$ & $85-115$ & $97.6(6 \cdot 1) t$ & $85-110$ \\
\hline Body mass index $\left(\mathrm{kg} / \mathrm{m}^{2}\right)$ & $26 \cdot 7(3 \cdot 2)$ & $20 \cdot 0-32 \cdot 3$ & $26.6(3.5)$ & $18 \cdot 6-32 \cdot 9$ \\
\hline Serum cholesterol $(\mathrm{mmol} / \mathrm{l})$ & $5.95(1 \cdot 1) \ddagger$ & $3 \cdot 7-8 \cdot 1$ & $5.98(0.9) \S$ & $4 \cdot 1-8 \cdot 1$ \\
\hline$\gamma$-Glutamyltransferase (IU) & $27 \cdot 6(20 \cdot 4) \dagger$ & $5-81$ & $24.8(14.5) \dagger$ & $6-80$ \\
\hline Left ventricular mass $(\mathrm{g})$ & $247 \cdot 0(46 \cdot 3) \|$ & $164-341$ & $242.8(43.0) \dagger$ & $169-360$ \\
\hline \multicolumn{5}{|c|}{ Mean resting blood pressure $(\mathrm{mm} \mathrm{Hg})$ : } \\
\hline Systolic & $139.8(11 \cdot 8)$ & $114-177$ & $140 \cdot 1(14 \cdot 8)$ & $112-168$ \\
\hline Diastolic & $93.0(5 \cdot 8)$ & $80-104$ & $91.9(6.5)$ & $79-104$ \\
\hline \multicolumn{5}{|c|}{ Mean ambulatory blood pressure $(\mathrm{mm} \mathrm{Hg})$ : } \\
\hline Systolic & $133.7(14 \cdot 6)$ & $106-177$ & $132.6(13.8)$ & $107-166$ \\
\hline Diastolic & $93 \cdot 5(7 \cdot 3)$ & $76-107$ & $93.8(5 \cdot 8) \varsigma$ & $84-109$ \\
\hline
\end{tabular}

Results from ${ }^{\star} 41$ patients, $\nmid 44$ patients, $¥ 47$ patients, $§ 46$ patients, $\| 45$ patients

TABLE II-Comparison of mildly hypertensive patients at start and end of six months' stress management or mild exercise. Results are means (standard errors)

\begin{tabular}{|c|c|c|c|c|}
\hline & \multicolumn{2}{|c|}{ Stress management } & \multicolumn{2}{|c|}{ Mild exercise } \\
\hline & Start & End & Start & End \\
\hline \multicolumn{5}{|c|}{ Mean resting blood pressure $(\mathrm{mm} \mathrm{Hg})^{\star}$ : } \\
\hline Systolic & $140 \cdot 1(1.9)$ & $140 \cdot 7(2 \cdot 4)$ & $141 \cdot 0(2 \cdot 4)$ & $141 \cdot 8(2 \cdot 6)$ \\
\hline Diastolic (phase V) & $92.5(0.9)$ & $92.4(1.5)$ & $91 \cdot 4(1 \cdot 0)$ & $91 \cdot 8(1.6)$ \\
\hline \multicolumn{5}{|c|}{ Mean ambulatory blood pressure $(\mathrm{mm} \mathrm{Hg}) \mathrm{t}$ : } \\
\hline Systolic & $133.5(2.7)$ & $132 \cdot 7(2 \cdot 6)$ & $132 \cdot 4(2 \cdot 2)$ & $132 \cdot 1(3 \cdot 0)$ \\
\hline Diastolic (phase V) & $92 \cdot 6(1 \cdot 2)$ & $93 \cdot 8(1 \cdot 3)$ & $93.4(1.0)$ & $93.8(1.2)$ \\
\hline Left ventricular mass $(\mathrm{g}) \ddagger$ & $238 \cdot 2(8 \cdot 4)$ & $239 \cdot 4(9 \cdot 2)$ & $235 \cdot 8(7 \cdot 7)$ & $228 \cdot 4(7 \cdot 7)$ \\
\hline
\end{tabular}

^Results from 43 patients practising stress management and 41 taking exercise.

†Results from 36 patients practising stress management and 37 taking exercise.

$\ddagger$ Results from 33 patients practising stress management and 30 taking exercise

TABLE III-Mean (standard error) blood pressure $(\mathrm{mm} \mathrm{Hg})$ of mildly hypertensive patients taken with automatic sphygmomanometer before and after stressful interviews at start and end of six months' stress management or mild exercise

\begin{tabular}{|c|c|c|c|c|}
\hline & \multicolumn{2}{|c|}{$\begin{array}{l}\text { Stress management } \\
\qquad(n=41)\end{array}$} & \multicolumn{2}{|c|}{$\begin{array}{l}\text { Mild exercise } \\
\quad(n=41)\end{array}$} \\
\hline & Start & End & Start & End \\
\hline \multicolumn{5}{|l|}{ Systolic: } \\
\hline Before interview & $144 \cdot 3(2 \cdot 0)$ & $142 \cdot 1(2 \cdot 4)$ & $144 \cdot 2(2 \cdot 4)$ & $140 \cdot 6(2.5)$ \\
\hline After interview & $151 \cdot 7(2 \cdot 4)$ & $145 \cdot 8(2 \cdot 1)$ & $148 \cdot 2(2.5)$ & $149.0(2.9)$ \\
\hline \multicolumn{5}{|c|}{ Diastolic (phase y). } \\
\hline Before interview & $94 \cdot 0(1 \cdot 1)$ & $92.5(1.5)$ & $92 \cdot 7(1.5)$ & $90 \cdot 1(1.5)$ \\
\hline After interview & $98 \cdot 5(1 \cdot 3)$ & $95 \cdot 3(1 \cdot 4)$ & $95 \cdot 6(1 \cdot 4)$ & $94.9(1.5)$ \\
\hline
\end{tabular}

TABLE IV-Mean (standard error) resting blood pressure ( $\mathrm{mm} \mathrm{Hg}$ ) of mildly hypertensive patients taken manually and automatically at start and end of six months' stress management or mild exercise and at six month follow up

\begin{tabular}{|c|c|c|c|c|c|c|}
\hline & \multicolumn{3}{|c|}{ Stress management $(n=40)$} & \multicolumn{3}{|c|}{ Control $(n=32)$} \\
\hline & Start & End & Follow up & Start & End & Follow up \\
\hline \multicolumn{7}{|c|}{ Pressure taken manually ${ }^{\star}$ : } \\
\hline Systolic & $139 \cdot 1(1 \cdot 8)$ & $140 \cdot 2(2 \cdot 2)$ & $140.9(2.0)$ & $136 \cdot 4(2 \cdot 4)$ & $138.0(2.6)$ & $134 \cdot 7(2 \cdot 3)$ \\
\hline Diastolic (phase V) & $92 \cdot 1(0.9)$ & $92 \cdot 6(1 \cdot 6)$ & $92.9(1.2)$ & $89 \cdot 4(1 \cdot 1)$ & $90 \cdot 0(1 \cdot 7)$ & $90.0(1.7)$ \\
\hline \multicolumn{7}{|c|}{ Pressure taken automaticallyt: } \\
\hline $\begin{array}{l}\text { Systolic } \\
\text {. }\end{array}$ & $142.0(2 \cdot 1)$ & $140 \cdot 7(2 \cdot 2)$ & $140 \cdot 7(2 \cdot 0)$ & $139 \cdot 0(2 \cdot 0)$ & $135 \cdot 8(2 \cdot 3)$ & $137.4(2.7)$ \\
\hline Diastolic (phase V) & $93.6(1 \cdot 2)$ & $92.9(1.5)$ & $93 \cdot 3(1 \cdot 3)$ & $90 \cdot 3(1 \cdot 4)$ & $88 \cdot 0(1 \cdot 5)$ & $90 \cdot 0(1.9)$ \\
\hline
\end{tabular}

^Taken with Hawksley sphygmomanometer.

†Taken with Takeda sphygmomanometer. of those taking mild exercise: two failed to attend any sessions for treatment; in one, blood pressure was above the specified limit on three successive sessions; eight dropped out variously believing that they no longer needed treatment, that they could not spare the time, or that treatment was unhelpful; and one was prescribed antihypertensive drug treatment by her general practitioner. The patients who withdrew from treatment would not agree to a repeat assessment, and we did not include them in the primary analysis of the effects of treatment. Patients who did not adhere fully to the regimen of treatment but who did not withdraw from the study were included in the final analysis. We could not obtain satisfactory ambulatory records for some patients, especially overweight subjects. This is a common problem when measuring ambulatory pressure. ${ }^{19}$

The patients who completed treatment were similar to the total sample (table II). Neither the resting blood pressure nor the ambulatory blood pressure was reduced by either treatment, nor was there any difference between the treatments. We calculated the simple differences between the treatments in the change in pressure during treatment: the difference in the change in resting systolic blood pressure was 0.2 (95\% confidence interval $-6 \cdot 2$ to $6 \cdot 6) \mathrm{mm} \mathrm{Hg}$; the difference in the change in resting diastolic blood pressure was $-0.3(-4.3$ to 3.7$) \mathrm{mm} \mathrm{Hg}$; the difference in the change in ambulatory systolic blood pressure was $0 \cdot 4(-5 \cdot 0$ to $5 \cdot 8) \mathrm{mm} \mathrm{Hg}$; and the difference in the change in ambulatory diastolic blood pressure was $-0.8(-3.8$ to 2.2$) \mathrm{mm} \mathrm{Hg}$. Left ventricular mass did not change and did not differ between the groups (table II): the difference in the change in left ventricular mass during treatment was $8 \cdot 7(-16.3$ to 33.7$) \mathrm{g}$. Because of technical and scheduling problems satisfactory echocardiograms were obtained on two occasions in only 63 subjects, but these records were representative of the initial pool of records.

Since some patients dropped out of the study and data from other patients were incomplete all the analyses were repeated using an intention to treat analysis in which missing data were replaced by the patient's data from the baseline assessment. The findings were unchanged: blood pressure did not drop, nor was there any significant difference between the treatments.

Table III shows the blood pressure measured automatically before and after the mildly stressful interviews. Systolic blood pressure was higher after the interview in both groups before and after treatment $(F 1,80=39.55, p<0.001)$, but the rise was smaller in the patients who had completed the course of stress management $(\mathrm{F} 1,80=4 \cdot 79, \mathrm{p}<0.05)$. The results for diastolic pressure were similar, the comparable $\mathrm{F}$ ratios being $34.68(\mathrm{p}<0.001)$ and $3.81(\mathrm{p}<0.06)$.

We reassessed the patients' blood pressure six months after the post-treatment assessment, but three patients from the stress management group and nine from the exercise group were unavailable for follow up (six were receiving antihypertensive drugs, four refused to attend, one was receiving treatment for an unrelated condition, and one had left the district). Blood pressure had not changed at follow up (table IV). The figure shows the blood pressure of patients who completed all phases of the study. The only substantial drop in pressure occurred during the three month baseline period.

At the end of treatment patients completed a questionnaire on relevant activities, which showed that patients in the stress management group carried out more relaxation and those in the exercise group carried out more exercise. The patients in the two groups did not differ in the extent to which they claimed that they successfully managed stress. 
- Stress management $(n=36)$ - - Mild exercise $(n=30)$

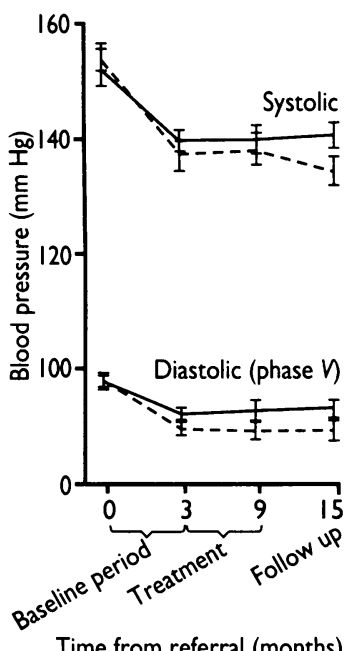

Time from referral (months) Means (SE) systolic and diastolic blood pressure of mildly hypertensive patients from their referral to follow up

\section{Discussion}

In this study neither stress management nor mild exercise had a detectable effect on the blood pressure of patients with mild primary hypertension when pressure was measured under controlled clinical conditions or when it was measured automatically every 30 minutes during a normal 12 hour day. Furthermore, treatment had no detectable effect on the left ventricular mass measured by echocardiography. The fact that more patients dropped out from the exercise group might, however, reflect the patients' or their doctors' dissatisfaction with this treatment.

Previous studies with programmes of stress management that were identical, ${ }^{18}$ similar, ${ }^{56}$ or broadly comparable $^{8-12}$ to ours mostly showed that such treatment lowered pressure significantly and by a greater amount than a variety of control procedures, ${ }^{5681011}$ including the exercises used in this study.$^{18}$ Although other recent studies have also failed to detect any difference between stress management and contro conditions, ${ }^{912021}$ this study is unusual in not finding any reduction in blood pressure after treatment. The differences between our results and those of previous studies are probably not due to differences in the treatment because the form of stress management used was simple and easy to conduct, was virtually identical with the methods we had used previously, ${ }^{18}$ and was delivered by experienced clinical psychologists who standardised their procedures. The sample was large for a study of this kind, and the results were unequivocal. We cannot say if our patients were comparable with previous subjects since very different patient populations have been used in the various studies. The patients in this study were probably more representative of the mildly hypertensive population than those studied previously.

The most striking difference between this and comparable studies is the long baseline period when patients measured their blood pressure frequently. It is well established that hypertensive patients' blood pressure drops with habituation to clinical procedure and repeated measurements of blood pressure..$^{22}$ When our patients attended for the pretreatment assessment they were presumably well habituated to measuring blood pressure, and only patients whose blood pressure still met the entry criteria entered the study. This contrasts with previous studies, in which pressure was often measured infrequently ${ }^{5811}$ or the drop in pressure during the baseline period was not a criterion for exclusion. ${ }^{18}$ Of the patients who attended for pretreatment assessment, $21 \%$ were excluded because their blood pressure was too low, and although the pressure of those admitted to the study had also dropped from the referral value, those excluded showed a much greater drop from a referral pressure of $153 \cdot 5 / 96 \cdot 3 \mathrm{~mm} \mathrm{Hg}$ to $127 \cdot 6 / 80 \cdot 5 \mathrm{~mm} \mathrm{Hg}$.

We may therefore have habituated patients to measurement of blood pressure and excluded those who showed the greatest reductions in pressure with habituation. Other studies may have confounded the effect of habituation with that of stress management. This would not, however, explain the differences between stress management and comparison treatments in reducing blood pressure since they would share the same lack of habituation before treatment. This suggests that stress management increases the speed of habituation or enhances a related process in reducing pressure, a possibility that we have raised previously. ${ }^{23}$ This is consistent with the finding that stress management has a short term advantage over repeated measurement of blood pressure in reducing blood pressure but that this disappears over a prolonged follow up as blood pressure continues to fall in those receiving repeated measurements. ${ }^{12}$
The only positive finding in this study was that the slight pressor response associated with the stressful interview was reduced after stress management. This may represent the effects of stress management on enhancing the speed of habituation to a pressor stimulus.

This study suggests that stress management of a type often advocated to treat mild primary hypertension has no detectable effect on either the resting clinic or ambulatory blood pressure of hypertensive patients who are well habituated to the measurement of blood pressure. Simple stress management may help lower the pressure at the time of measurement in patients who are not well habituated to the procedure, but such reductions are unlikely to be clinically important. If stress management does reduce the risk of cardiovascular disease ${ }^{14}$ it is unlikely to be solely by reducing blood pressure. ${ }^{13}$ Future studies of stress management and other behavioural methods of controlling hypertension should include a substantial baseline period for frequent measurements of blood pressure to stabilise the pressure before treatment is started. The same may also be true in the routine clinical management of mildly hypertensive patients.

We thank the Medical Research Council for its financial support, the participating practices for their help at all phases of the study, and Dr Paul Bennett for letting us use his treatment related behaviour questionnaire.

1 Pooling Project Research Group. Relation of blood pressure, serum cholesterol, smoking habit, relative weight and ECG abnormalities to incidence of majo coronary events: final report of the pooling project. Fournal of Chronic Diseases 1978;31:201-306

2 Cutler JA, MacMahon SW, Furberg CD. Controlled clinical trials of drug treatment for hypertension. Hypertension 1989;13(suppl I):I-36-44.

3 MacMahon S, Cutler JA, Stamler J. Antihypertensive drug treatment: potential, expected, and observed effects on stroke and on coronary heart potential, expected, and observed effects on
disease. Hypertension 1989;13(suppl I):I-45-50.

4 Medical Research Council Working Party. Adverse reactions to bendrofluazide and propranolol for the treatment of mild hypertension. Lancet 1981;ii: $539-43$

5 Patel C, North WRS. Randomised controlled trial of yoga and biofeedback in the management of hypertension. Lancet 1975;ii:93-5.

6 Patel C, Marmot MG, Terry DJ. Controlled trial of biofeedback-aide behavioural methods in reducing mild hypertension. $B M F$ 1981;282: 2005-8.

7 Patel C, Marmot M. Can general practitioners use training in relaxation an management of stress to reduce mild hypertension? BMF 1988;296:21-4

8 Bennett P, Wallace L, Carroll D, Smiths N. Treating type A behaviours and mild hypertension in middle-aged men. $f$ Psychosom Res 1990;35:209-33.

9 Chesney MA, Black GW, Swan GE, Ward MM. Relaxation training for Csential hypertension at the worksite. I. The untreated mild hypertensive. Psychosom Med 1987;49:250-63.

10 Southam MA, Agras WS, Taylor CB, Kraemer HC. Relaxation training: blood pressure during the working day. Arch Gen Psychiatry 1982;39:715-7.

11 Taylor CB, Farquhar JW, Nelson E, Agras WS. Relaxation therapy and high blood pressure. Arch Gen Psychiatry 1977;34:339-42.

12 Agras WS, Taylor CB, Kraemer HC, Southam MA, Schneider JA. Relaxation training for essential hypertension at the worksite. II. The poorly controlle hypertensive. Psychosom Med 1987;49:264-73.

3 Johnston DW. Stress management in the treatment of mild primary hypertension. Hypertension 1991;17(suppl III):III-63-8.

14 Patel C, Marmot MG, Terry DJ, Carruthers M, Hunt B, Patel M. Trial of relaxation in reducing coronary risk: four year follow up. $B M \mathcal{F} 1985 ; 290$ 1103-6.

15 Diem K, Lenter C. Scientific tables, documenta Geigy. Basle: J R Geigy, 1970.

16 Rosenman RH, Friedman M, Strauss R, Wurm M, Kositchek R, Hahn W, al. A predictive study of coronary heart disease. JAMA 1964;189:15-22.

17 Pocock SJ, Simon R. Sequential treatment assignment with balancing for prognostic factors in the controlled clinical trial. Biometrics 1975;31:103-15.

18 Irvine J, Johnston DW, Jenner D, Marie GV. Relaxation and stress management in the treatment of essential hypertension. I Psychosom Res 1986;30:437-50.

19 Pickering TG. Ambulatory monitoring and blood pressure variability. London: Science Press, 1991

20 Van Montfrans GA, Karemaker JM, Weiling W, Dunning AJ. Relaxatio therapy and continuous ambulatory blood pressure in mild hypertension. $B M$ J 1990;300:1368-72.

21 Irvine MJ, Logan AG. Relaxation behavior therapy as sole treatment for mild hypertension. Psychosom Med 1991;53:587-97.

22 Medical Research Council Working Party. Randomised controlled trial of treatment for mild hypertension: design and pilot trial $B M \mathcal{F} 1977 ;$ $1437-40$.

23 Johnston DW. How does relaxation training reduce blood pressure in primar hypertension? In: Dembroski TD, Schmidt TH, Blumchen C, eds. hypertension? In: Dembroski TD, Schmidt TH, Blumchen C, eds. Verlag, 1986:550-67.

(Accepted 28 fanuary 1993) 